\title{
Renewable Energy Integrated Islanded Microgrid for Sustainable Irrigation-A Bangladesh Perspective
}

\author{
Md Asaduzzaman Shoeb (iD) and GM Shafiullah * \\ School of Engineering and Information Technology, Murdoch University, Perth 6150, Australia; \\ M.Shoeb@murdoch.edu.au \\ * Correspondence: g.shafiullah@murdoch.edu.au; Tel.: +61-8-9360-6417
}

Received: 5 April 2018; Accepted: 14 May 2018; Published: 17 May 2018

\begin{abstract}
Due to high investment and maintenance costs, the government on Bangladesh is unable to provide sufficient support for grid extension and supplying electricity to remote or rural areas. The deficit in electricity introduces a crisis in powering irrigation systems, which influences negatively the country's dominant income-generating sector, agriculture. Islanded microgrids with solar photovoltaic (PV) cells is one of the most attractive solutions for providing power to rural areas due to their cost-effectiveness, reliability and environment-friendly attributes. Therefore, a techno-economic feasibility study has been undertaken to investigate the prospects of renewable energy-based islanded microgrids to support rural electrification to power both households and irrigation systems. Three case studies based on the operation time of irrigation pumps during the day are developed using the HOMER Pro Microgrid Analysis Tool to identify the optimised configurations for the proposed system. The optimised configurations are then assessed considering the performance matrices of the cost of electricity (COE), net present cost (NPC), greenhouse gas (GHG) emissions and renewable energy fraction (RF). From the analyses, it is perceived that the operation of irrigation pumps at different times of a day is a significant influence, and the optimum method considering techno-economical evaluation is to run the irrigation pumps during the daytime by solar PV. It is evident that the proposed islanded microgrid has significant potentialities in powering irrigation systems as well as rural electrification with low energy generation costs, a contribution to the reduction of global warming and to ameliorating the energy crisis in Bangladesh in order to achieve a sustainable future.
\end{abstract}

Keywords: energy crisis; irrigation; microgrid; solar photovoltaic (PV); Bangladesh

\section{Introduction}

Global energy demand is increasing daily with the growth of population. More than 1.2 billion people or roughly a quarter of the global population in the world do not have reliable electricity including over 50 million people in Africa and 300 million people in India [1]. Most of the rural areas that are far from mainland urban areas lack access to energy services as well as, modern facilities, which is considered a significant global development challenge. However, affordable and clean energy, stated in Goal 7 of the Sustainable Development Goals (SDGs), is one of the key enablers for the SDGs introduced by the United Nations Development Programme (UNDP) in January 2016. The main agenda of the goal is to ensure reliable, sustainable and efficient electricity to all [2]. Most countries are currently working towards achieving this goal. Moreover, currently the energy is being mainly supplied from fossil fueled power generation that contributes greenhouse gas (GHG) emissions which adversely affects global climate conditions [1,3]. In contrast to fossil fuels, renewable energy (RE) sources like solar, wind, hydro, geothermal, tidal, biomass, etc. are the most suitable alternatives for providing emission-free, sustainable and clean energy for society. 
Due to high initial investment and maintenance costs, governments, particularly in the developing countries, are becoming more reluctant to provide capital funding for grid extensions to deliver electricity to remote locations or rural areas. Hence, rural areas have either no electricity or have small-scale stand-alone power systems, such as diesel generator-based power systems, often without renewable energy sources or with only small scale solar photovoltaic (PV) systems to supply power. RE integrated systems concentrating on a small entity encourages interest worldwide in providing more sustainable forms of energy to remote populations. Therefore, a small unit of such a power system, called a microgrid (MG) or minigrid, can be considered as a viable solution to maintain continuity of power supply in the rural community for critical loads as well as support reduction in GHG emissions by utilising available renewable sources effectively. A microgrid is a low-voltage distribution network, and it can either be grid-connected or an off-grid autonomous system [1,4,5].

From the available research, it is evident that hybrid power systems with RE sources can be reliable, cost-economic, effective and more sustainable compared to either grid-connected or stand-alone generators utilising a single fossil fuel-based power source [1,4,5]. Many countries around the world such as, Bangladesh, India, South Africa, and Australia are currently doing in-depth research to deploy microgrid-based energy-efficient and reliable power systems for rural communities [4-9].

In Bangladesh, approximately $75 \%$ of the population in rural areas have no electricity in their homes [10]. Efficient electricity supply is necessary for the economic development of the country as well as delivery of key public services, including health, education, and infrastructure [11]. Access to consistent and sustainable electricity can help support income-generating activity, in particular to support irrigation which contributes $16 \%$ of the country's GDP [12].

Bangladesh possesses a significant potential for electricity generation from renewable energy resources such as solar PV, wind, hydro and biomass. Solar PV has been an emerging technology for the last decade in Bangladesh, mainly in the form of solar home systems (SHS) in rural areas, which can only meet the basic demands of individual households. There are a few off-grid minigrid hybrid systems developed with solar PV that are in operation now $[7,8,13]$.

Bangladesh's government has taken many initiatives to utilise renewable energy sources, particularly solar PV, to address the electricity crisis of remote areas [14]. The solar home system (SHS) was initiated in 2003 to provide electricity to the remote communities of Bangladesh and gained worldwide recognition. Up to May 2017, approximately 4.12 million SHSs have been installed throughout the country under this program, which is cost-effective and environment-friendly [15]. These small electricity access systems consist of a 20-100 Wp solar panel, a lead acid battery, a charge controller and basic loads currently providing reliable electricity to more than 16 million people in off-grid remote areas. However, major limitations of this electrification option include: affordability of the poorest demographic segment [16]; limitations to utilising the energy for productive purposes [17] as the systems often suffer from excess capacity because they are generally designed over-sized to ensure high reliability; and the systems are not flexible regarding usage patterns and payment methods [18]. Moreover, a field-based investigation identified several shortcomings, mostly during the implementation stage, such as poor quality components, poor installation, and absence of quality control mechanisms [7].

Islanded microgrids with distributed energy resources, also referred to as minigrids in literature, have been increasingly attractive in recent years in the rural areas of Bangladesh as they can provide reliable power to the community. A detailed study of the hybrid minigrid project in Bangladesh is discussed in [7] and [8]. Chowdhury et al. [7] indicate that the minigrid can be a useful tool to achieve the Sustainable Energy Access for All (SE4A) [19] goals as the proposed hybrid minigrid system is technically and economically viable for Bangladesh. In addition to techno-economic analysis, Bhattacharyya [8] presented a business case analysis of a minigrid-based electrification system for Bangladesh. Model results show that low-energy consumers will pay almost one-half of the cost of owning an SHS for a comparable level of energy use. However, the proposed system is not economically viable if the consumer uses a high volume of energy, which requires significant upfront 
costs. A large-scale minigrid also introduces energy losses during the off-peak period. Therefore, the author suggested a small-scale mini-grid based electricity supply that provides a basic level of electricity to consumers.

On the other hand, electricity is also a critical need for irrigation purposes in the agricultural sector, which employs approximately $47 \%$ of the total labour force in Bangladesh [2]. More than $80 \%$ of the entire population depends on agriculture either directly or indirectly [20]. Bangladesh will be self-sustaining in food grain production if adequate irrigation facilities can be provided. Natural rainwater is almost sufficient for irrigation during rainy seasons; however, the irrigation requirement is quite high all over Bangladesh during dry seasons [21]. As electricity is not available in the rural areas, diesel generators are widely used for irrigation, which is not only a costly solution but also emits GHG into the atmosphere. Solar-based irrigation systems have started to be used recently in Bangladesh due to the availability of solar exposure, easy installation and the declining price of solar panels. The solar photovoltaic (PV) water pumping system is one of the reliable, efficient and cost-effective irrigation systems that meet energy demands and contribute to the socio-economic development of Bangladesh [20,21]. To increase the country's irrigated land area as well as food production, the government of Bangladesh took the initiative to install 10,000 solar-powered irrigation pumps by 2016 which would save US $\$ 100$ million in fuel subsidy costs over 20 years and reduce $\mathrm{CO}_{2}$ emissions by an annual 126,000 tons [20]. However, solar pumping is not suitable for very high demand as the capacity of the single unit is very low. The water yield of the solar pump changes according to variation in solar radiation. Hence, it is mostly suitable for using at noon while the solar exposure is maximum in order to benefit maximally [22]. Moreover, the irrigation systems should minimise water losses and be built with control mechanisms that ensure efficient water utilisation.

From literature and research, it is evident that RE-based power systems are available that can power the electrical loads (SHS, hybrid minigrid systems) and irrigation systems (solar PV pumping) for the rural areas of Bangladesh. However, there is no research available that has analysed the impact of powering both the community loads and irrigation systems from a single microgrid or minigrid system. Recently, a preliminary analysis was conducted to investigate the suitability of a solar PV-based hybrid power system for different scenarios of irrigation load [23]. Further research with refined data has been proposed in this study to develop a fully-fledged sustainable electrification solution for the remote communities of Bangladesh that can provide power to the community and irrigation systems efficiently with less cost. This current research aims to investigate the potentialities of a microgrid with distributed energy resources for rural areas considering cost-economic and environmental benefits using the HOMER Pro Microgrid Analysis Tool [24]. Outcomes of this research will be a useful tool for power utilities and government bodies in their planning for deployment of distributed energy-based microgrids for rural communities to supply power to the community and irrigation systems. The proposed research method can be used in any remote areas or any islands to identify the techno-economic aspects for deployment of a distributed energy-based islanded microgrid considering indigenous parameters such as renewable energy resources potential, community load profile, irrigation demand, and cost of equipment for the individual areas.

\section{Islanded Microgrid System}

This study proposes the development of a renewable energy integrated microgrid system in the rural areas of Bangladesh to support community loads and irrigation systems. A remote rural area $(22.0470 \mathrm{~N}, 90.630 \mathrm{E})$ located at the southern part of Bhola, the biggest island of Bangladesh, is considered as the case study site as shown in Figure 1. The area consists of a large marketplace, a couple of schools, mosques and general residential load, and has an irrigation demand for approximately 50 hectares of land during dry periods. 


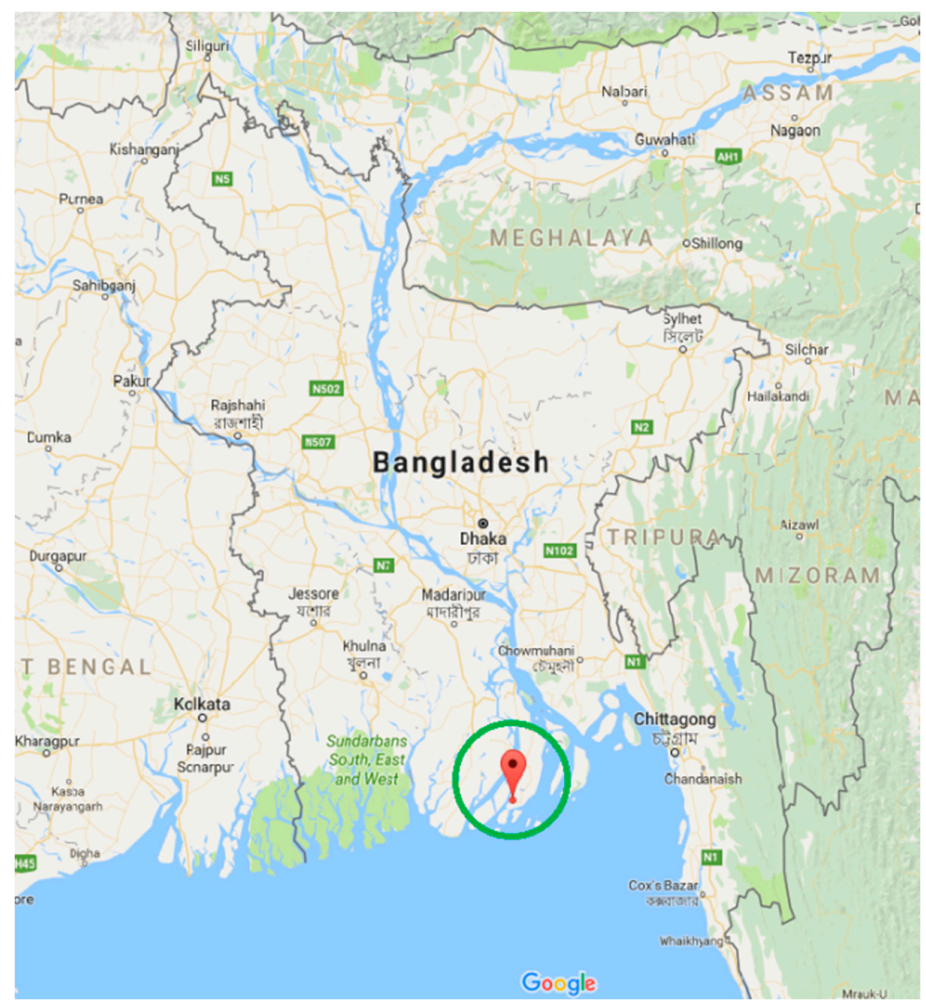

Figure 1. Location on the map of the selected site (map source: www.maps.google.com).

The proposed hybrid system comprises of solar PV, diesel generators, battery, converters, and loads. From the primary analyses, it can be observed that using two different diesel generators instead of one is economic and increases the reliability of the system and decreases the overall fuel consumption, and hence this study has considered two diesel generators. All the PV panels are connected to the grid through the inverter, and the battery bank is connected through a bi-directional inverter as depicted in Figure 2. The site demography and energy consumption pattern are analysed to estimate the prospective load for the hybrid microgrid system. Different sizes and combinations of equipment are simulated and analysed for various load patterns to reach the optimal design of the hybrid microgrid for the selected area.

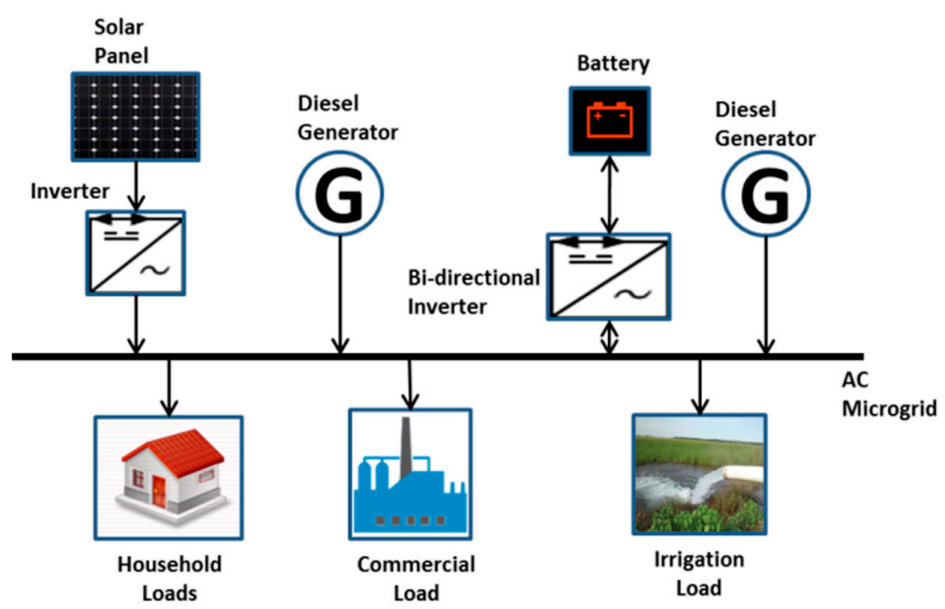

Figure 2. Renewable energy integrated islanded microgrid. 


\subsection{Load Analysis}

The typical electricity consumption in rural areas/villages is not high compared to the urban areas of Bangladesh. The significant loads are in the form of lighting and cooling (fans). With the introduction of the microgrid, a better growth of commercial loads in the likes of sawmills, husking mills, and grinding mills is expected and, accordingly, the energy consumption trend and pattern are assumed to change in a way that increases the daytime load significantly. Moreover, irrigation pumps are also expected to play a key role in the daily load consumption pattern based on the control and design of the system.

The energy usage pattern of rural populations within the existing microgrid areas is described in [7,25]. It is shown in [25] that the major energy consumption is not coming from the lighting and cooling load, rather, the appliances run by the motor are consuming the greatest proportion of the electricity. The motor-based appliances are mainly industrial machines that include air compressors, wood-working tools, marble/wood cutters, lathe machines, etc. Hence, the commercial loads are increasing with the introduction of the hybrid microgrid, and most of these loads are operated during the daytime. On the other hand, there is a significant demand for irrigation during the dry season. The irrigation loads mainly depend on the type of crops and total area for irrigation [26,27]. Moreover, as the mobile telecommunication networks are expanding rapidly in Bangladesh, the base transceiver stations can be powered from the microgrids in the rural areas.

In this study, the loads of the selected site have been divided into two categories.

Primary load: this includes the domestic load, community (schools, mosques) load, and commercial load. The primary loads are formulated based on the socio-economic condition and current trend of the energy consumption of the site. The energy consumption pattern of minigrids mentioned in $[7,25,28]$ and the field survey conducted in [29] are also taken into consideration for load estimation. Figure 3 shows the primary load curve of a typical day in summer and winter. A high daytime load is estimated because of the expected industrial growth with the introduction of the microgrid. However, the demand in summer is generally higher than that of winter, mainly because of the high cooling demand. Typical seasonal and daily variations of the primary load are shown in Figure 4.

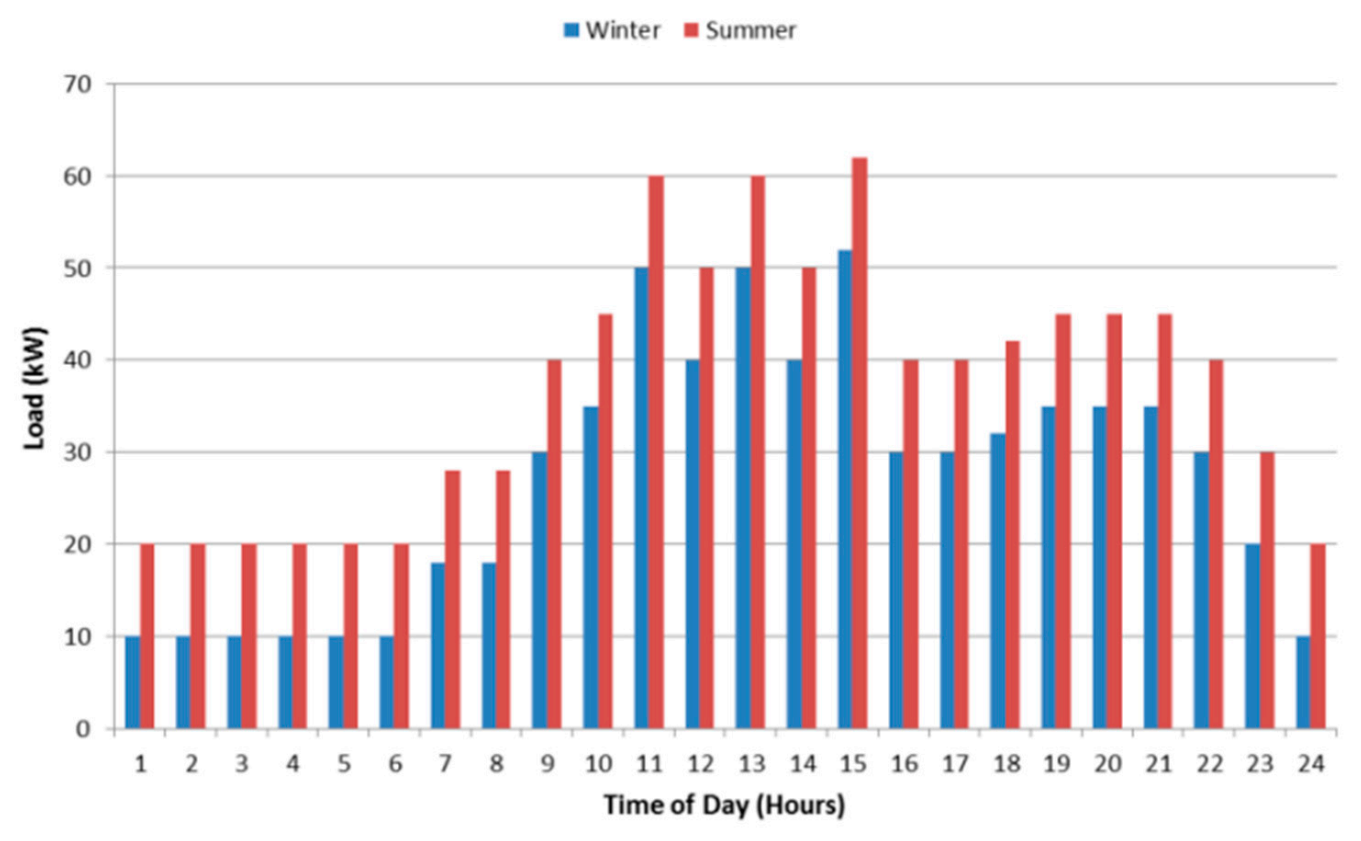

Figure 3. Typical load curve of primary load. 

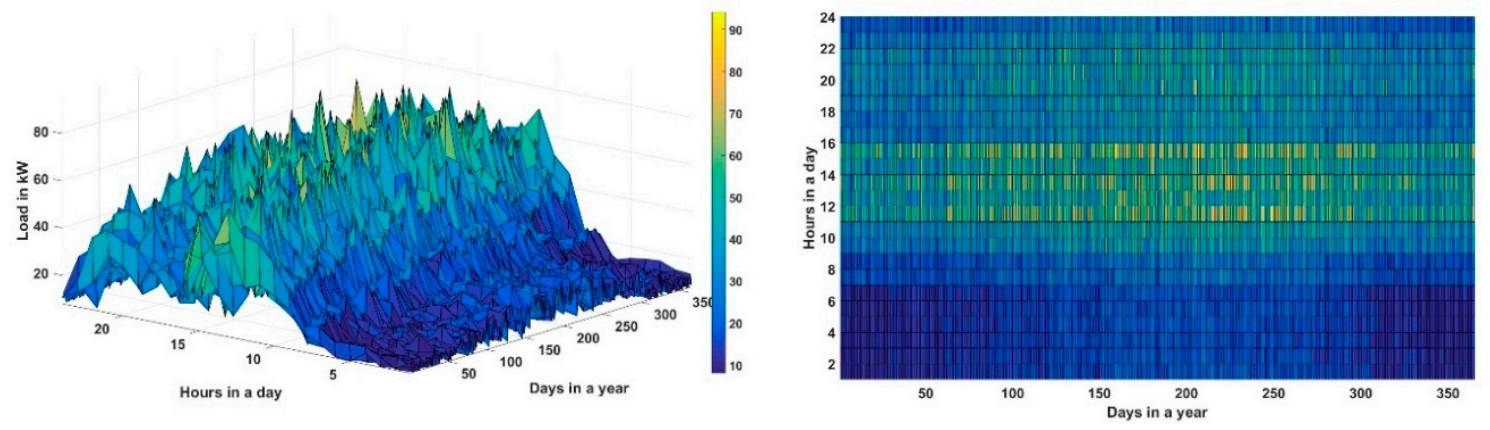

Figure 4. Daily and seasonal variations of primary load (in kW).

Irrigation load: in Bangladesh, the period from November to April has no or little rainfall. However, this is a major cultivation period and it, therefore, requires irrigation. The main crops that are cultivated during the dry season include boro rice, wheat, potato, maize, tomato, pulses and winter vegetables. However, among these crops, boro rice requires more than $90 \%$ of the irrigation [27]. Therefore, in this study, the irrigation load for boro is taken into consideration. Based on various statistics found in the literature it has been estimated that, for the southern part of Bangladesh, approximately $6000 \mathrm{~m}^{3}$ of irrigation water is required per month per hectare of land for boro rice [27,30,31]. In this study, it is estimated that 20 irrigation pumps of $2 \mathrm{~kW}$ power rating are required to irrigate 50 hectares of land of the selected area from November to May. The irrigation pumps need to run on average $9 \mathrm{~h}$ each day to meet the irrigation demand [7,30]. Figure 5 shows the average energy required per month for irrigation.

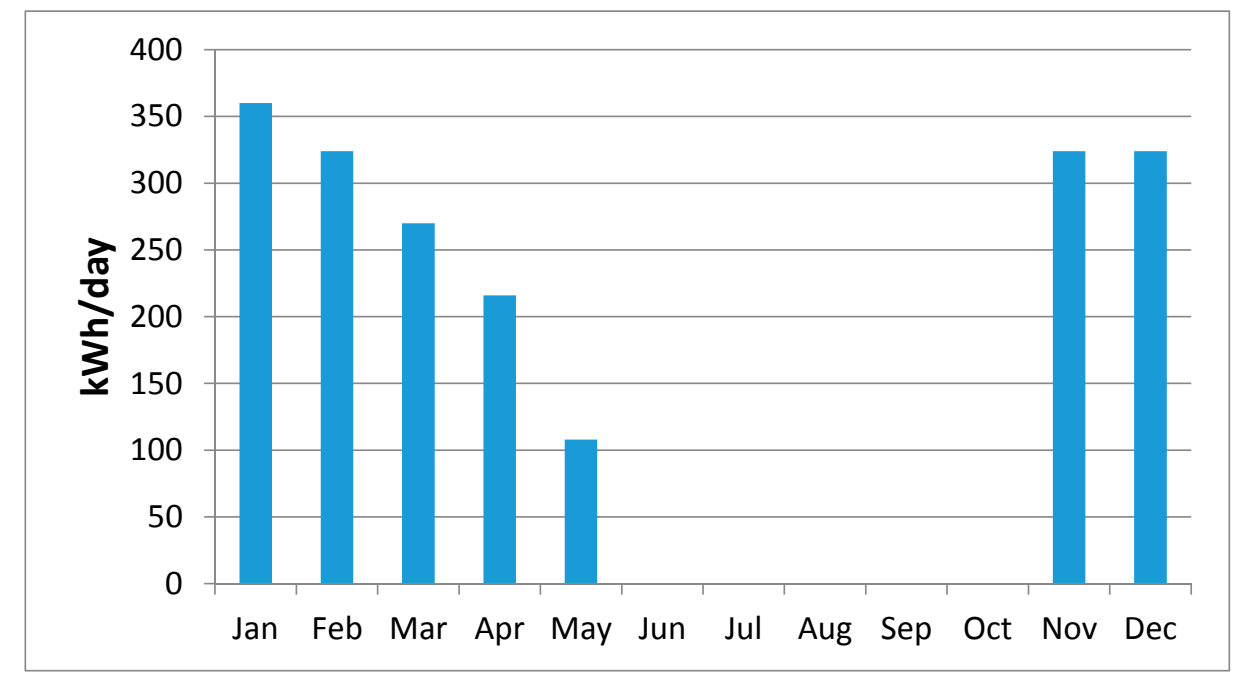

Figure 5. Average monthly irrigation load throughout the year.

\subsection{Study Case Development}

During the dry season, the irrigation pumps are required to run for around $9 \mathrm{~h}$ in a day. The electricity demand of the 20 irrigation pumps of $2 \mathrm{~kW}$ accounts for a significant value compared to the primary load. Therefore, the period of running the irrigation pumps has a significant impact on the hybrid microgrid system sizing and operation strategy. Three case scenarios have been developed in this study based on the time of running the irrigation pumps. 


\subsubsection{Case-1}

In this case study, the irrigation load is considered as the deferrable load and added with the primary load. Deferrable load is the electrical load that must be met within some period, but the exact timing is not important [24]. Therefore, the irrigation pumps are expected to run based on the condition of the other loads and generations. In this case, the irrigation pumps need to run $9 \mathrm{~h}$ in a day and these $9 \mathrm{~h}$ can be any time within the $24 \mathrm{~h}$ of any day.

\subsubsection{Case-2}

The irrigation pumps operate only during the day, from 9 a.m. to 6 p.m. while there is a reasonable solar generation available. In this case study, the irrigation pumps are merged with the primary load and, hence, daytime load has increased significantly along with the peak load being changed.

\subsubsection{Case-3}

In this case study, the irrigation pumps run only from 11 p.m. to 8 a.m. while there is no generation from solar PV. The irrigation pumps are merged with the primary load and the system peak load is significantly decreased compared to Case 2 .

\section{System Modelling}

The hybrid microgrid analysis software HOMER Pro [24,32] is a powerful tool for techno-economic analysis of microgrids. The three case scenarios stated earlier are modelled in HOMER to identify the optimal system configuration of the hybrid system. The schematic system designs considered for the simulations are shown in Figure 6.

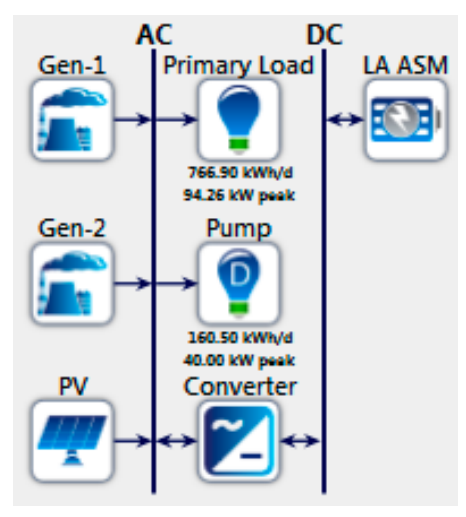

Case-1

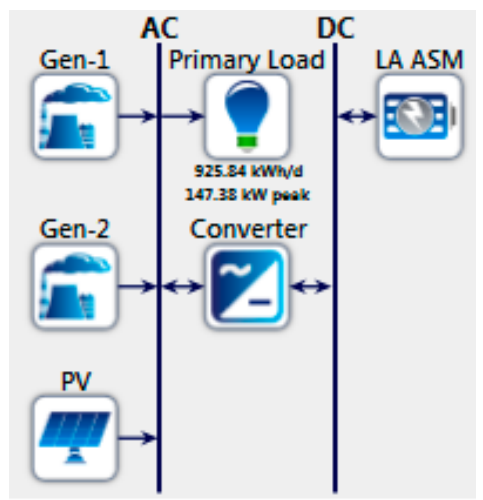

Case-2

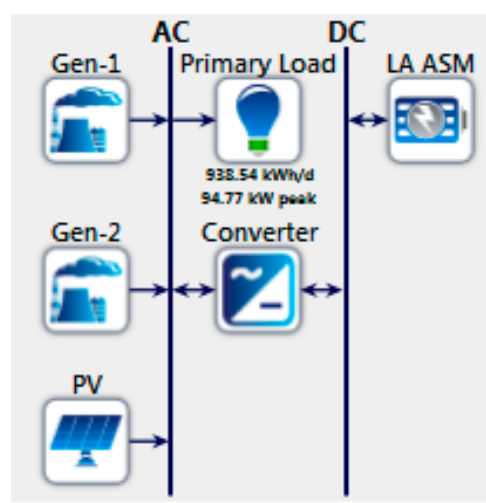

Case-3

Figure 6. System design for the three selected cases.

\subsection{Optimisation Constraints}

To maintain the system's reliability and efficiency, the case studies are analysed considering the following constraints:

Capacity shortage: the total capacity deficiency that occurs throughout the year is called the annual capacity shortage. The ratio of annual capacity shortage and total annual electrical demand is termed the capacity shortage fraction as shown in Equation (1).

$$
f_{c s}=\frac{E_{c s}}{E_{\text {demand }}}
$$

where $E_{c s}$ is the annual capacity shortage in $\mathrm{kWh} / \mathrm{yr}$, and $E_{\text {demand }}$ is the annual electrical demand in $\mathrm{kWh} / \mathrm{yr}$. 
The systems that have a higher capacity shortage fraction value than the maximum allowable capacity shortage fraction are considered as unacceptable. In this study, the maximum allowable capacity shortage is considered as zero. Hence, the systems are designed in such a way that there is no capacity shortage; the entire demand should be met. It is worth mentioning that the demand includes the operating reserve.

Renewable fraction: the renewable fraction $\left(f_{\text {ren }}\right)$ is the contribution of the renewable energy sources to meet the load. It is calculated using Equation (2):

$$
f_{\text {ren }}=1-\frac{E_{\text {nonren }}}{E_{\text {served }}}
$$

where $E_{\text {nonren }}$ is the non-renewable energy production in $\mathrm{kWh} / \mathrm{yr}$, and $E_{\text {served }}$ is the total energy production in $\mathrm{kWh} / \mathrm{yr}$.

In this work, the accepted minimum renewable fraction is set as zero to observe the systems with and without solar PV.

Operating reserve: a surplus operating capacity that ensures reliable and smooth operation in case of a sudden failure/incident. In this study, the operating reserve is considered as $10 \%$ of the current load and $25 \%$ of the solar power output of any time step.

\subsection{Dispatch Strategy}

Being a system, which is a combination of renewable energy sources, a storage device (battery), and diesel generators, a specific dispatch strategy is essential. Dispatch strategy refers to the set of rules to control operation of the diesel generators and to charge and discharge the battery under different circumstances. Several dispatch strategies for hybrid power systems are discussed in [32,33]. However, in this study, only two dispatch strategies are considered, these being cycle charging (CC) and load following (LF) [34]. In the CC strategy, the prime role of the generators is to serve the primary load. Excess generation after meeting the primary load is used to serve the deferrable load and charging the battery bank. However, there is a provision to restrict the amount of charging of the battery bank from the generators by means of "Set-point State of Charge". In the LF strategy, the generators operate only to serve the primary load (and operating reserve). Charging the battery bank and serving deferrable load is the responsibility of the renewable energy sources.

The diesel-off operation is enabled in this study; diesel generators are not required to run just to support grid frequency and voltage. The inverters used in the microgrid are expected to have grid-forming capabilities. Multiple generators are also allowed to run at the same time if needed.

\subsection{Model Input}

Solar PV: Generic flat-plate PV without a tracking mechanism is considered in this study. Considering the available area of the selected site, the maximum size of the PV panels is limited to $300 \mathrm{kWp}$. Flat-plate PV arrays absorb global horizontal irradiation (GHI) to convert it into electricity. GHI accounts for the summation of direct beam radiation, diffuse radiation and any reflected radiation. Therefore, GHI is the main input data required to calculate the PV output power. GHI of the study area is collected from the National Aeronautics and Space Administration (NASA) Surface Meteorology and Solar Energy data [35]. The annual average solar radiation is $4.52 \mathrm{kWh} / \mathrm{m}^{2} /$ day and it is evident that, in the middle of the year from June to September, the incident solar radiation is comparatively low, mainly due to poor clearness index of the rainy season as shown in Figure 7. However, solar radiation is comparatively high in the months of February to May. Another input parameter is a derating factor which is a scaling factor to consider the reduced output in practical operating conditions due to soiling of the panels, wiring losses, shading, aging, and temperature (if not modelled separately).

Generator: Diesel fueled gensets are considered in this study. The generators are regulate to operate at least $25 \%$ of their capacity, and once started will run a minimum of $30 \mathrm{~min}$. The generators are named as Gen-1 and Gen-2. 
Battery: In this study, one string consists of 24 generic $1 \mathrm{kWh}$ lead acid (LA) batteries which result in string voltage of $48 \mathrm{~V}$. The initial and minimum state of charge (SOC) of the batteries is considered as $0 \%$ and $40 \%$ respectively.

The sizes of different equipment considered for optimisation and sensitivity analysis are shown in Table 1. However, these values are considered based on the knowledge gained from several trial simulations. The capability of HOMER to select the optimised size from a range is used for the LA battery string, PV array, and system converter.

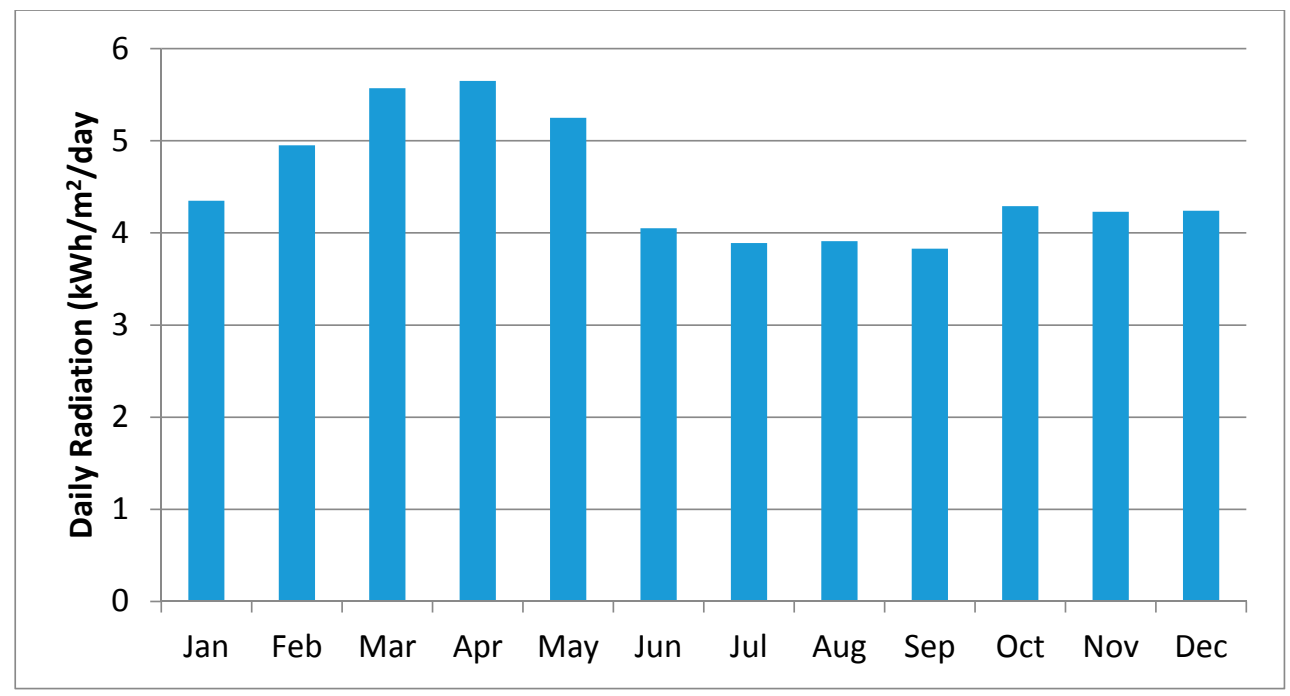

Figure 7. Monthly average solar irradiation in the study area.

Economic input: The economic input plays an important role in optimal design of the hybrid system. The costs of different components of the system are taken from [28] which are based on the local market in Bangladesh and follow the standard required by the Infrastructure Development Company Limited (IDCOL). The estimated cost of the components is given in Table 2. The cost of diesel is considered as USD $\$ 0.80 / \mathrm{L}$. The project lifetime considered for this work is 25 years.

Table 1. Sizes for optimisation of different equipment.

\begin{tabular}{cc}
\hline Equipment & Considered Sizes \\
\hline Gen-1(kW) & $0,20,30,50,60,70$ \\
Gen-2 $(\mathrm{kW})$ & $0,20,30,50,60$ \\
Photovoltaic (PV) dedicated converter $(\mathrm{kW})$ & $60,70,80,90,100,110,120$ \\
Lead acid (LA) battery (Number of string) & Minimum: 0 and Maximum: 100 \\
PV capacity $(\mathrm{kW})$ & Minimum:0 and Maximum: 300 \\
System converter $(\mathrm{kW})$ & Minimum: 0 and Maximum: 300 \\
\hline
\end{tabular}

Table 2. Equipment initial cost * [28].

\begin{tabular}{cccc}
\hline Component & Unit Cost & Replacement Cost & O\&M cost \\
\hline Generic flat panel PV & $600 / \mathrm{kW}$ & $400 / \mathrm{kW}$ & $10 /$ year $/ \mathrm{kW}$ \\
Diesel generator & $500 / \mathrm{kW}$ & $400 / \mathrm{kW}$ & $0.03 / \mathrm{h} / \mathrm{kW}$ \\
LA battery & $175 /$ battery & $150 / \mathrm{battery}$ & $20 /$ year $/ \mathrm{battery}$ \\
Converter & $250 / \mathrm{kW}$ & $200 / \mathrm{kW}$ & $5 /$ year $/ \mathrm{kW}$ \\
\hline
\end{tabular}

${ }^{*}$ costs are in USD. O\&D—operation and maintenance. 


\subsection{Performance Metrics}

HOMER simulates different combinations with available component sizes in search space to determine the feasible combinations and ranks the feasible combinations based on the net present cost (NPC). The NPC of a system is the present value of all the costs of installing and operating that component over the project lifetime, minus the present value of all the revenues that it earns over the project lifetime. The cost includes capital cost, replacement cost, operation and maintenance (O\&M) cost, fuel cost and emission penalties. However, levelised cost of electricity (COE) is also a useful metric to measure the cost of the systems. COE is the average cost per $\mathrm{kWh}$ of useful electrical energy produced by the system [24]. In this study, the emissions incurred from any system are also considered along with NPC and COE to select the optimum system.

\section{Results and Analysis}

Optimal system performance analyses have been carried out to evaluate the performance of the proposed hybrid microgrid system. Possible feasible combinations are identified based on the given constraints and inputs, and are ranked based on their NPC and COE.

Cycle charging (CC) dispatch is found as the optimal strategy for all the combinations considered for Case- 1 as shown in Table 3. Combination 1 comprising $208 \mathrm{kWp}$ of PV, two generators of $30 \mathrm{~kW}$ and $50 \mathrm{~kW}$ and a string of batteries is the most economical system for Case- 1 as shown in Table 3. This system is also contributing minimum $\mathrm{CO}_{2}$ emissions to the environment even though its renewable fraction is slightly lower than some other systems as the operating period of the diesel generators is comparatively low. Therefore, this design can be considered as the best system for Case- 1 from both the economic and environmental viewpoints.

The model also provides the time-series generation profile of each source to meet the load demand of the optimised systems. Figure 8 shows the daily profile of generation and load of the system for a random day of January (dry season) while irrigation is a mandatory requirement. The irrigation load is distributed throughout the whole day. The solar PV is sufficient to fulfil the load demand during the day while the diesel generators need to start at the end of a day, before sunset. The batteries are charged by redundant power from the diesel generators due to the minimum running time and minimum loading constraints (generators need to run at least $25 \%$ of loading and for 30 min once started). As the system for Case- 1 follows the CC dispatch strategy, the batteries are charged to at least $80 \%$ SOC once they start to charge. In this case, solar PV is enough to support the load during the day while generators provided power from sunset to sunrise. It was observed that the solar PV and diesel can almost fulfil the energy requirements and, hence, the size and autonomy $(0.5 \mathrm{~h})$ of the batteries are small. From Table 3, Combination 2, it is found that a system without a battery can run economically with a slightly higher fuel cost.

From Case- 2 model analyses, it has been determined that a system with $240 \mathrm{kWp}$ of PV, two generators of $20 \mathrm{~kW}$ and $50 \mathrm{~kW}$, and three strings of batteries is selected as the most economical system considering the given constraints and inputs with their economic and environmental parameters. Like Case-1, for all the combinations CC is also found as the optimum dispatch strategy for Case-2. In Case-2, load demand during the day is very high as the irrigation pumps are running during the daytime. Hence, solar PV is not enough to meet the demand always, which leads to the occasional starting of the generators as shown in Figure 9. However, there may be a few instances when generated solar power is more than the required load demand, particularly at the beginning of the day when the additional energy is used to charge the batteries. On the other hand, after midnight the load demand becomes too low. Therefore, a single generator and batteries take over the load and hence the capacity and autonomy $(1.5 \mathrm{~h})$ of the battery are comparatively higher. This may be useful during the rainy season when the solar PV output becomes more intermittent, and generators need to start frequently. 
Table 3. Economic and environmental parameters of different optimised systems for Case-1.

\begin{tabular}{|c|c|c|c|c|c|c|c|c|c|c|c|}
\hline Combination & PV (kW) & $\begin{array}{l}\text { PV-Inv. } \\
(\mathrm{kW})\end{array}$ & $\begin{array}{l}\text { Gen-1 } \\
(\mathrm{kW})\end{array}$ & $\begin{array}{c}\text { Gen-2 } \\
(k W)\end{array}$ & $\begin{array}{l}\text { Battery } \\
\text { (No.) }\end{array}$ & $\begin{array}{c}\text { Converter } \\
(\mathrm{kW})\end{array}$ & Dispatch & $\begin{array}{c}\text { Net Present } \\
\text { Cost (NPC) (M\$) }\end{array}$ & $\begin{array}{l}\text { Cost of Electricity } \\
\text { (COE) }(\$ / \mathrm{kWh})\end{array}$ & $\begin{array}{c}\text { Renewable Energy } \\
\text { Fraction (RF) (\%) }\end{array}$ & $\begin{array}{c}\mathrm{CO}_{2} \text { Emissions } \\
\text { (ton/yr) }\end{array}$ \\
\hline 1 & 208 & 90 & 30 & 50 & 24 & 11.7 & CC & 0.991 & 0.227 & 47 & 148.56 \\
\hline 2 & 236 & 100 & 30 & 50 & 0 & 0 & CC & 1.02 & 0.232 & 48 & 149.57 \\
\hline 3 & 267 & 90 & 50 & 0 & 120 & 17.5 & CC & 1.09 & 0.250 & 49 & 153.85 \\
\hline 4 & 267 & 90 & 0 & 50 & 120 & 17.5 & CC & 1.09 & 0.250 & 49 & 153.85 \\
\hline 5 & 271 & 110 & 70 & 0 & 0 & 0 & CC & 1.24 & 0.284 & 47 & 167.98 \\
\hline 6 & 0 & 0 & 30 & 50 & 72 & 6.72 & CC & 1.46 & 0.334 & 0 & 279.76 \\
\hline 7 & 0 & 0 & 30 & 60 & 0 & 0 & $\mathrm{CC}$ & 1.48 & 0.339 & 0 & 283.60 \\
\hline
\end{tabular}




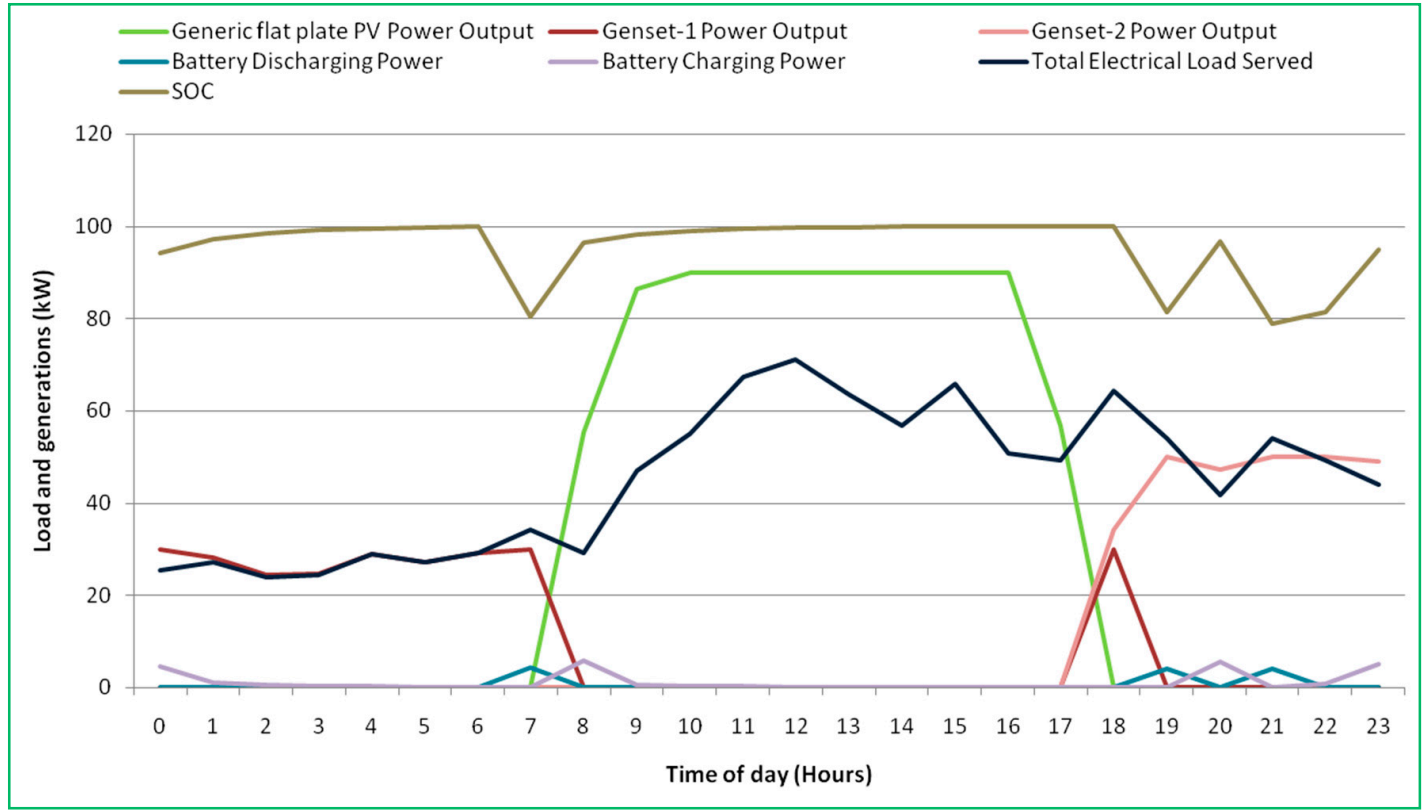

Figure 8. Load and generation on a random day of the dry season for the best combination of Case- 1 .

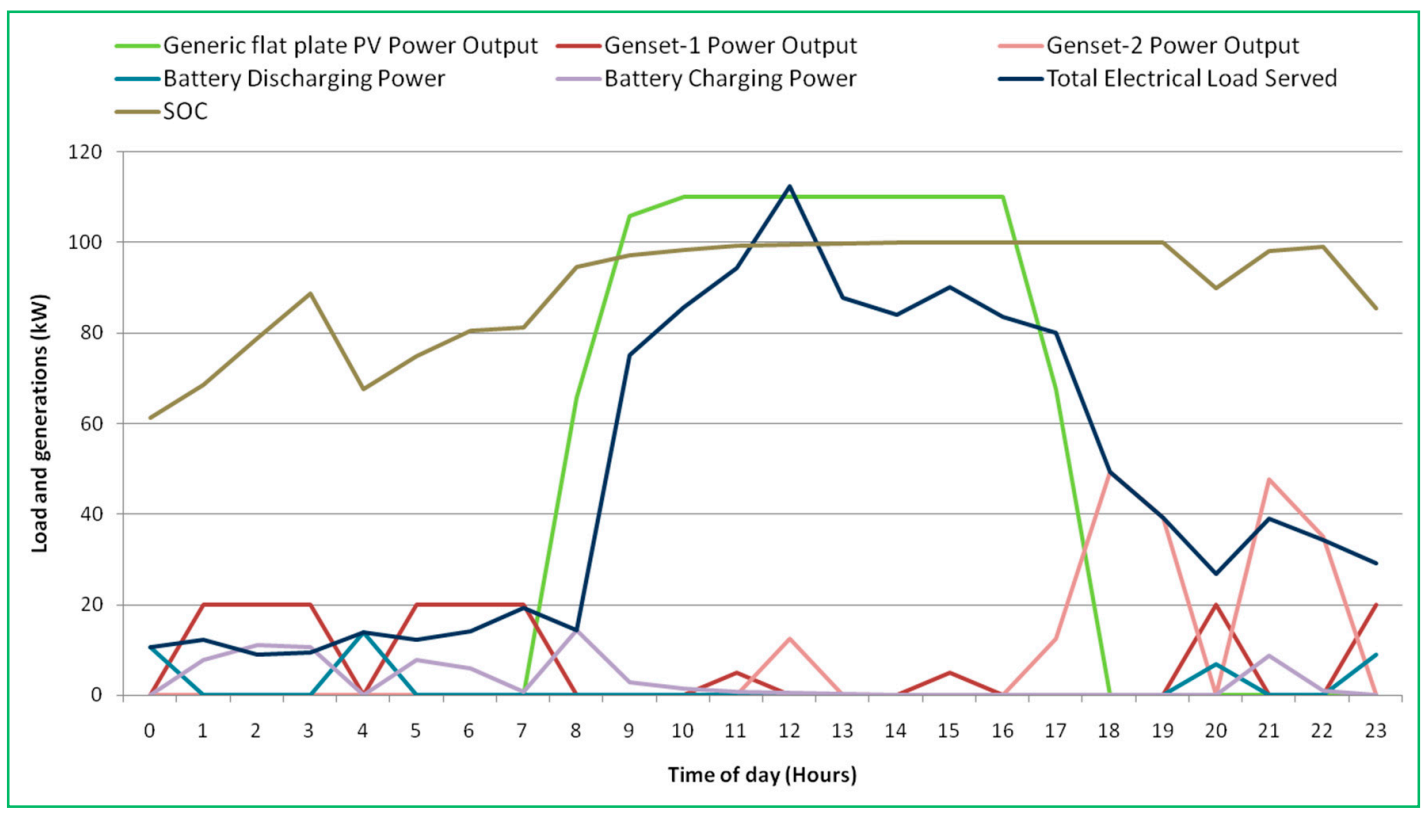

Figure 9. Load and generation on a random day of the dry season for the best combination of Case-2.

The combination comprising $208 \mathrm{kWp}$ of PV, two generators of $20 \mathrm{~kW}$ and $50 \mathrm{~kW}$, and 3 strings of batteries with a CC dispatch strategy is the best system for Case- 3 considering the economic and environmental parameters. The peak load occurs during the night in this case. Therefore, the generators need to contribute more, which results in a comparatively low renewable fraction and a high running cost due to fuel consumption.

As shown in Figure 10, the solar PV output is sufficient to meet the daytime load in this case. The maximum load occurs late at night when the irrigation pumps are running. The 1st generator starts to ramp up in the evening, and the 2nd generator provides additional support when required. The batteries are used to support the transition periods of the generators. Hence, the peak load of irrigation pumping is mostly met from the generators, which results in higher fuel costs and emissions. 


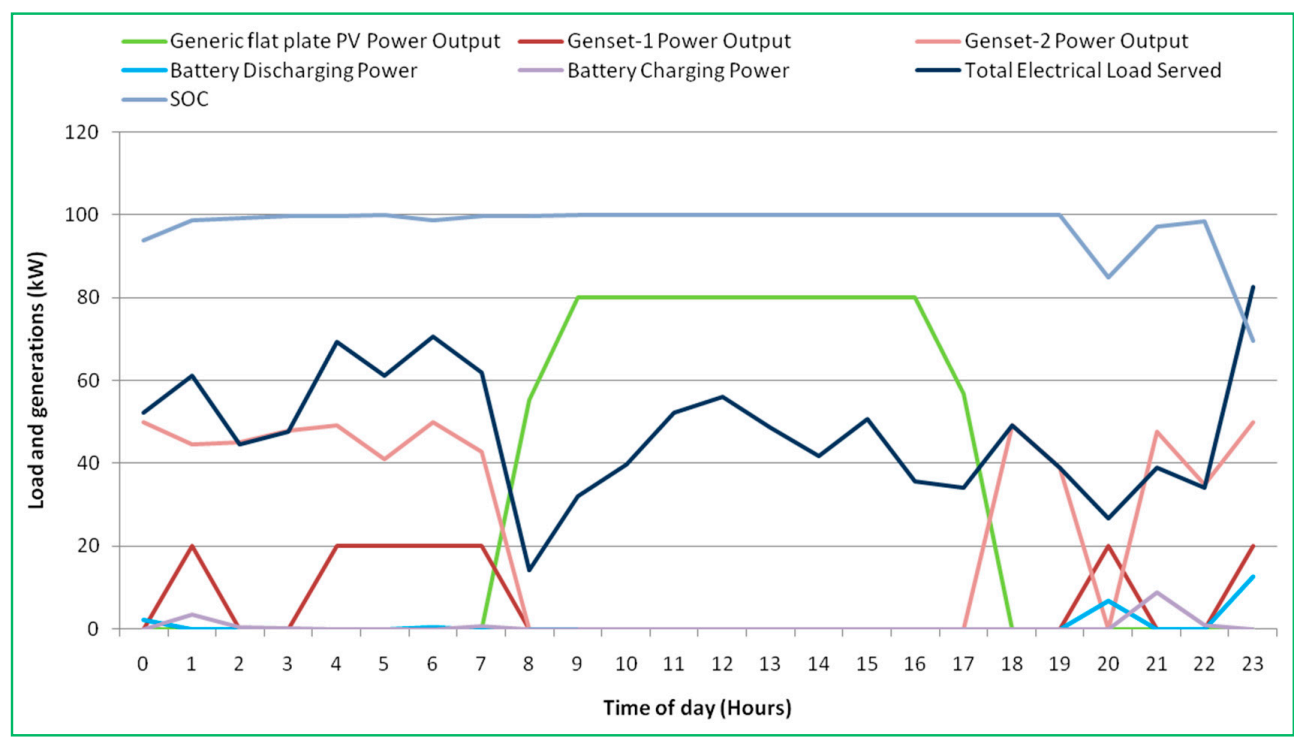

Figure 10. Load and generation in a typical day of the dry season for the best combination of Case-3.

The simulation results show that, for all the combinations in all three cases, the CC dispatch strategy is more economical than LF. Hence, batteries are always charged at least up to $80 \%$ of SOC once charging has started. In addition, the generators have a minimum running time and loading constraints. Hence, the batteries are charged by the generators on most occasions. In all cases, the batteries are economically sized to provide support during the transition periods rather than taking the bulk share of the load for long duration. However, in the LF dispatch strategy, the batteries are only charged by the solar PV and, as a result, the system would become very expensive to accommodate larger-sized PVs and batteries. It is also evident from the results that the systems without batteries are always slightly more expensive than the corresponding system with batteries as it requires running the diesel generators for a longer period when there is no battery.

The system comparison of the selected best system from each case is shown in Table 4 . From the results, it is found that in Case-3, the diesel generators are mostly used to fulfil the electricity requirements, as it needs to provide a greater amount of electricity during the night. In Case-2, solar PV can fulfil the demand as the irrigation pumps run during the day. Accordingly, in Case-2 the maximum solar output is $110 \mathrm{KW}$, whereas in Case- 1 and Case- 3 that value is $90 \mathrm{~kW}$ and $80 \mathrm{KW}$, respectively. Ultimately, Case-2 gets a greater contribution from the renewable energy source (solar PV) than the other two cases. However, it is possible to increase the renewable fraction further by adding more solar PV arrays to the system, but it would require more area to install and more upfront costs which is practically unfeasible.

Table 4. Comparison of the best system of each case.

\begin{tabular}{cccc}
\hline & Case-1 & Case-2 & Case-3 \\
\hline PV array size $(\mathrm{kWp})$ & 208 & 240 & 208 \\
Gen-1 size $(\mathrm{kW})$ & 30 & 20 & 20 \\
Gen-2 size $(\mathrm{kW})$ & 50 & 50 & 50 \\
Battery (number of batteries) & 24 & 72 & 48 \\
Converter size $(\mathrm{kW})$ & 11.7 & 15.4 & 12.6 \\
PV dedicated converter size $(\mathrm{kW})$ & 90 & 110 & 80 \\
NPC $(\mathrm{M} \$)$ & 0.991 & 0.847 & 0.989 \\
COE $($ \$ $/ \mathrm{kWh})$ & 0.227 & 0.217 & 0.249 \\
Renewable Fraction $(\%)$ & 47 & 55 & 40 \\
$\mathrm{CO}_{2}$ Emissions $(\mathrm{Kg} / \mathrm{Yr})$ & 148,562 & 124,418 & 168,631 \\
\hline
\end{tabular}


During the rainy season, the electricity demand is low without the irrigation load. However, it does not introduce significantly higher excess electricity into the system, as the generation from solar PV is low due to poor solar irradiance during rainy or cloudy days. Even the generators are often called upon to meet the demand during the day as depicted in Figure 11. On the other hand, there are instances of sunny days during the off-irrigation period, which results in some excess electricity as seen in Figure 12. As the systems are designed for the worst-case scenario to meet $100 \%$ of the demand over the year, it is difficult to avoid any excess electricity. Case- 2 has around $19 \%$ of excess electricity of the annual energy production with the other two cases having more than $25 \%$. Battery sizes can be increased with the LF dispatch strategy to store the excess energy; however, the simulation shows that it is not an economic option. Moreover, the capacity of the batteries would remain unused during the irrigation season. Other loads such as electric three-wheelers, electric bikes/boats can be encouraged during this period to consume the extra energy; even though it may require specific business and social policies for that.

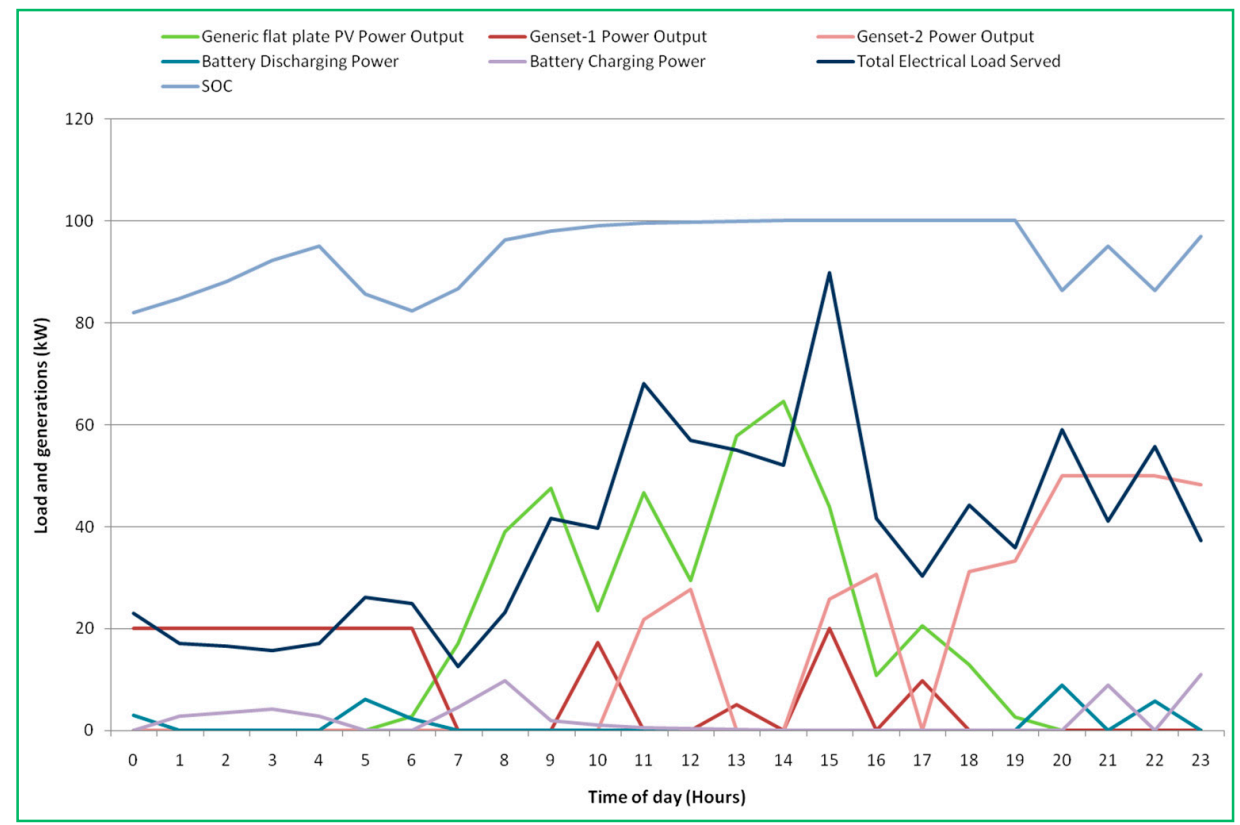

Figure 11. Rainy day without irrigation load for Case-2.

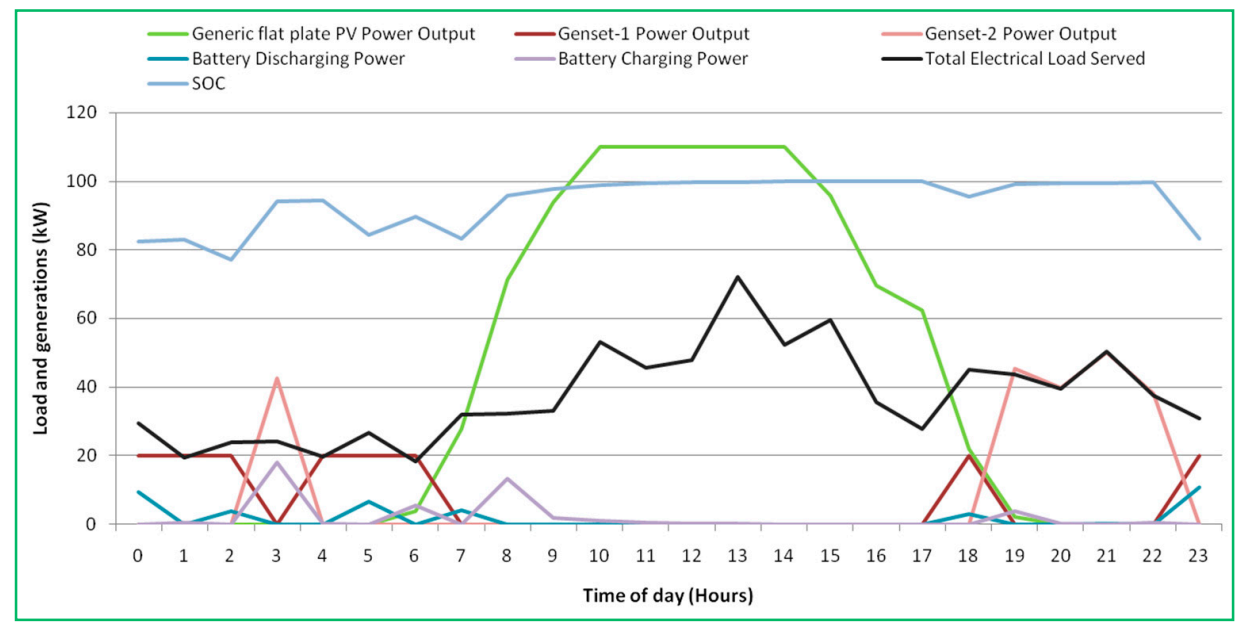

Figure 12. Sunny day without irrigation load for Case-2. 
The NPC and COE of the best systems for the three cases are shown in Figure 13a,b. The NPCs of Case-1, Case- 2 and Case- 3 are M $\$ 0.991, \mathrm{M} \$ 0.847$ and $\mathrm{M} \$ 0.989$, respectively, while the COEs of Case- 1 , Case-2 and Case-3 are $0.227 \$ / \mathrm{kWh}, 0.217 \$ / \mathrm{kWh}$ and $0.249 \$ / \mathrm{kWh}$, respectively. COE is the highest for Case- 3 as diesel generators are used for the maximum time. It is seen that, considering the whole project lifetime, the most severe cost is the fuel cost and systems that generate energy from the diesel generator are, therefore, more expensive. On the other hand, the initial cost of solar PV is very high and requires high upfront costs compared to the diesel generators. Therefore, Case- 2 has slightly higher capital cost but significantly lower fuel cost as shown in Figure 14. From the cost breakdown of the studied cases shown in Figure 14, it is seen that Case-2 requires the least cost with a minimum fuel cost. Hence, the total NPC of Case- 2 is lower than that of Case- 1 and Case- 3 as evident in Figure $13 \mathrm{~b}$. Figure 15 shows the costs incurred throughout the project lifetime from different items of equipment and it is seen that the highest cost incurred is from the gensets due to the cost of generators and diesel.

Figure 16 shows the $\mathrm{CO}_{2}$ emissions and renewable fraction for the studied three cases. Case-2 emits less $\mathrm{CO}_{2}$ and other GHGs compared to the other two cases as renewable energy contributes more than $50 \%$ of the energy in this system.

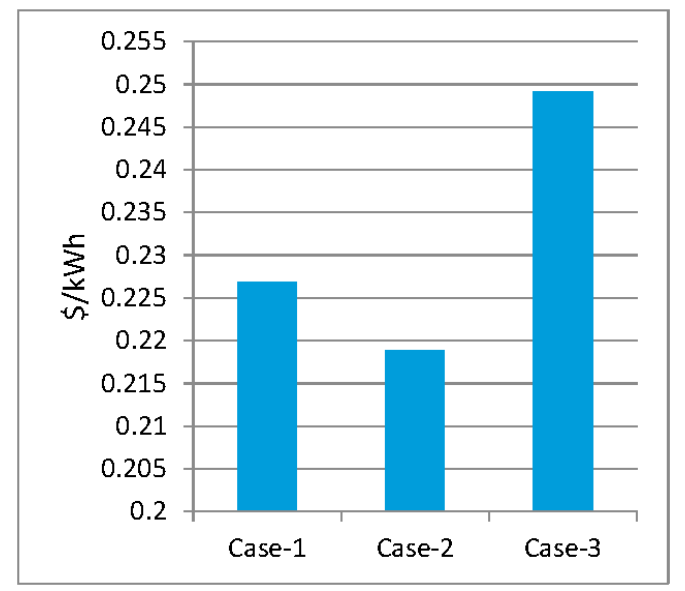

(a)

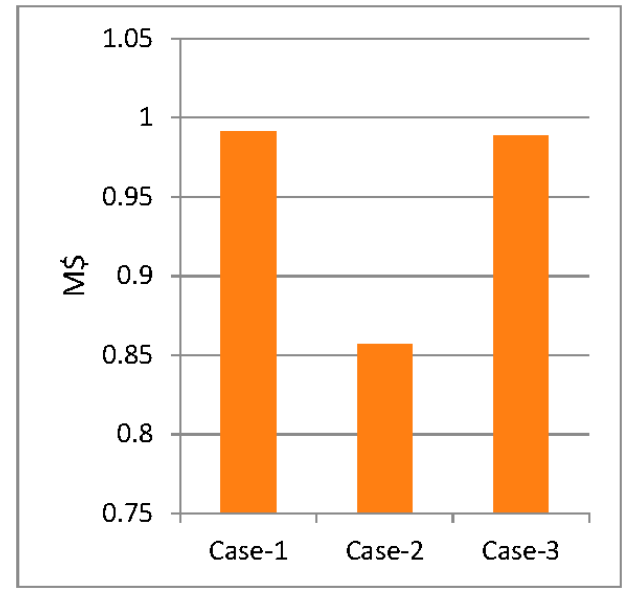

(b)

Figure 13. (a) Cost of electricity (COE) and (b) net present cost (NPC).

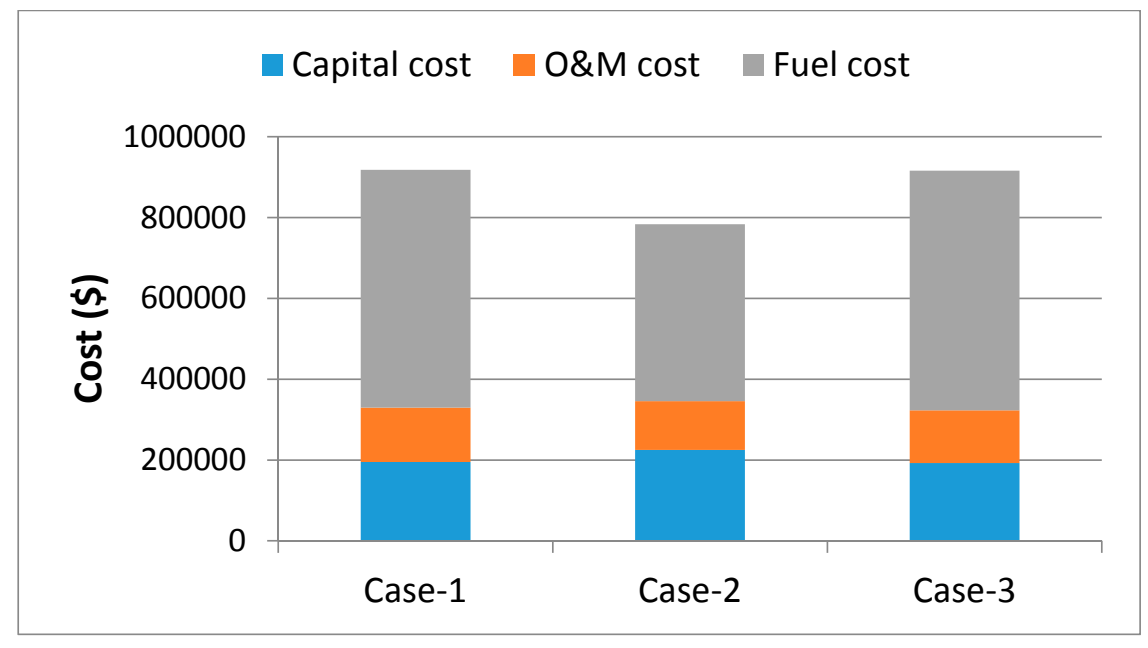

Figure 14. Cost breakdown. 


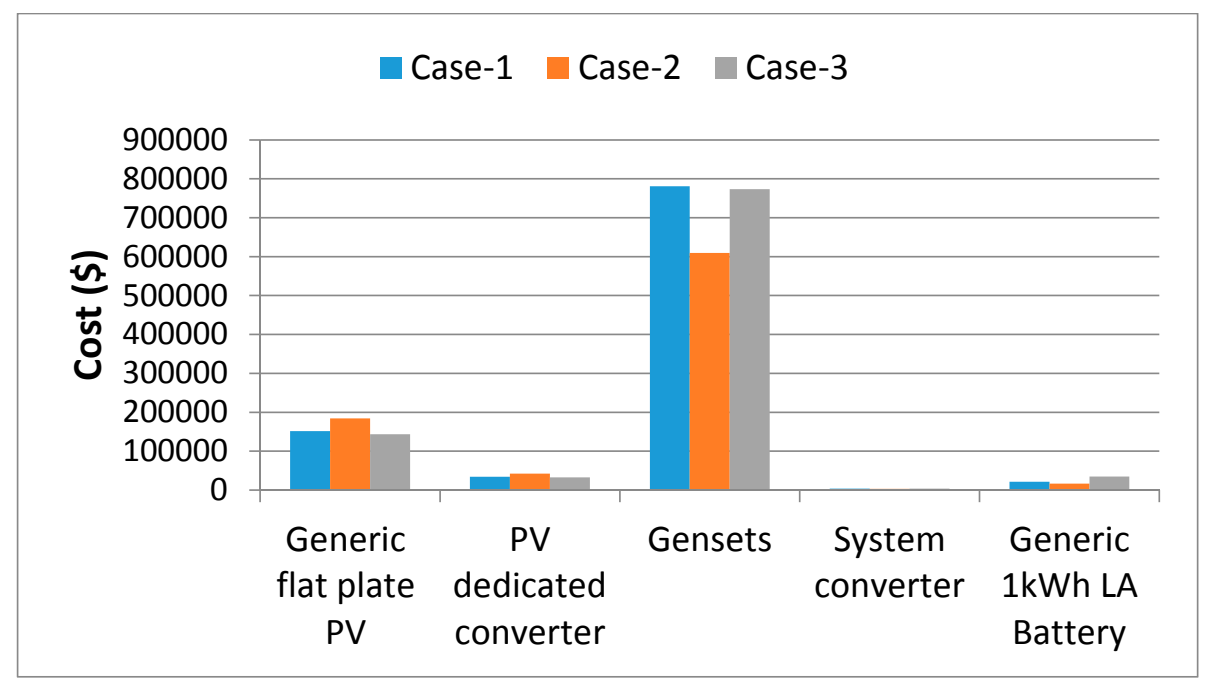

Figure 15. Cost incurred from different equipment.

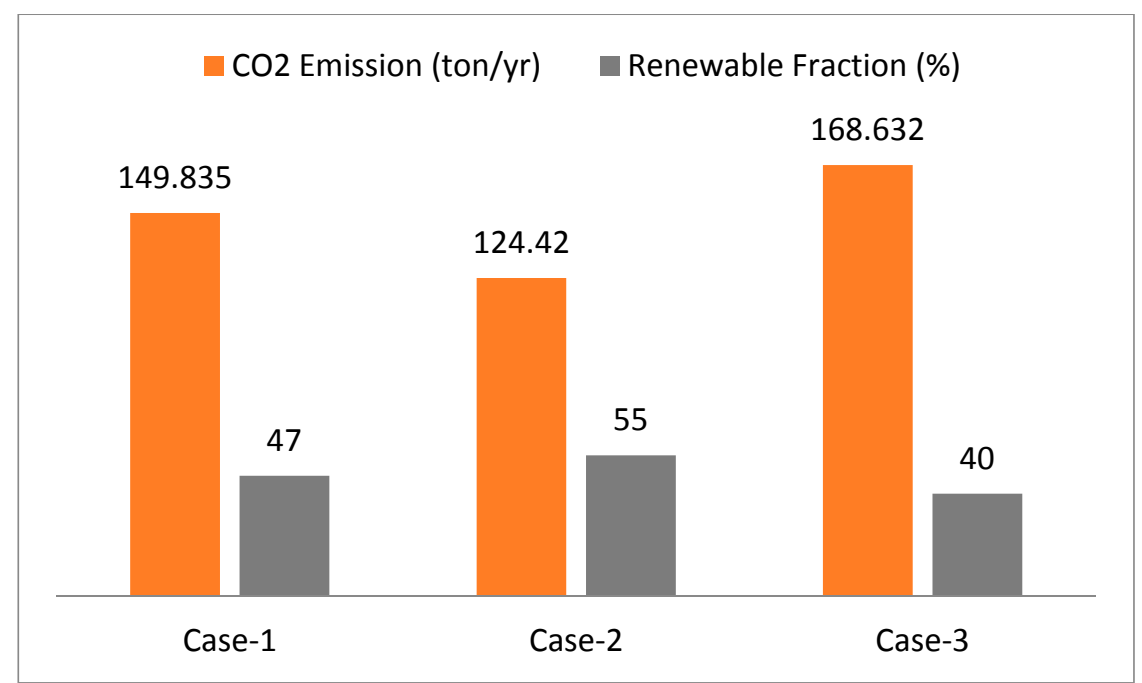

Figure 16. Renewable fraction and emissions incurred from the systems.

As identified from the simulation results, the systems using more diesel generators perform worst regarding emissions and cost. Case- 1 and Case- 3 need to depend on diesel generators for more than $50 \%$ of the required annual energy as the maximum load demand occurs after sunset. Therefore, in this study, Case- 2 involving running the irrigation pumps during the daytime is a suitable option considering both cost and environment. However, if in Case- 1 the irrigation demand was distributed throughout the day, this may facilitate the reduction of the capacity of the irrigation pumps. Therefore, considering the cost of irrigation pumps, Case- 1 would have better prospects. Finally, it can be concluded that all the considered cases are viable based on economic and environmental attributes, and the most suitable case for providing power to the community and irrigation systems is to operate the irrigation pumps only during the day in alignment with the availability of PV generation.

\section{Conclusions}

Bangladesh is working towards achieving the Sustainable Energy for All (SE4A) goals and aiming to ensure electricity for all by 2021 at a reasonable and affordable price. Moreover, the government is trying to develop a sustainable/economically viable irrigation system to boost the agricultural 
sector. Recently, renewable energy sources have attracted the attention of policymakers for developing energy systems and irrigation systems using these resources. In this study, a renewable energy integrated microgrid has been developed for powering the rural communities and irrigation systems of Bangladesh. From the analyses, it has been seen that the proposed system is not only cost-effective but also environmentally viable and fulfils the energy requirements of the community and irrigation systems. Significant findings from the study are:

- The time of operating irrigation pumps in a day during the dry season creates considerable differences in the load pattern of the system.

- From the analyses, it is found that daytime irrigation reduces GHG emission as solar PV can deliver the major portion of the energy requirements. Moreover, the levelised cost of electricity and the net present cost are also comparatively lower in this case.

- The cost of the equipment and fuel plays a critical role in the sizing and operation of the system.

- It has been observed that a load following dispatch strategy is required to gain a very high renewable fraction where batteries are totally charged by the solar PV. However, in this study, a cycle charging dispatch strategy is deemed economical for all three cases.

This research can be used by policymakers and industrialists as a useful guideline in their planning for deploying a renewable energy-based microgrid system in rural communities. Further research is required in the following areas to develop an inclusive hybrid renewable energy integrated microgrid systems for the future:

- Develop an optimum control strategy to manage energy demand of the community and irrigation systems efficiently.

- Develop a business case model involving policymakers and stakeholders.

- Investigate the variable generation scenarios due to unpredictable solar PV.

Author Contributions: Conceptualization, M.S. and G.M.; Methodology, M.S. and G.M.; Modelling, M.S. and G.M.; Validation, M.S. and G.M.; Formal Analysis, M.S. and G.M.; Investigation, M.S. and G.M.; Writing-Original Draft Preparation, M.S.; Writing-Review \& Editing, G.M.; Supervision, G.M.

Funding: This research received no external funding.

Acknowledgments: The authors would like to thank Infrastructure Development Company Limited (IDCOL) for their support by providing the necessary information at different stages of the research.

Conflicts of Interest: The authors declare no conflict of interest.

\section{References}

1. Schnitzer, D.; Lounsbury, D.; Carvallo, J.; Deshmukh, R.; Apt, J.; Kammen, D.M. Microgrids for Rural Electrification; United Nations Foundation: New York, NY, USA, 2014.

2. UNDP. UNDP Support to the Implementation of Sustainable Development Goal 7: Affordable and Clean Energy; United Nations Development Programme: New York, NY, USA, 2016.

3. Romankiewicz, J.; Qu, M.; Marnay, C.; Zhou, N. International Microgrid Assessment: Governance, INcentives, and Experience (IMAGINE); Ernest Orlando Lawrence Berkeley National Laboratory: Berkeley, CA, USA, 2013.

4. Shaahid, S.; El-Amin, I. Techno-economic evaluation of off-grid hybrid photovoltaic-diesel-battery power systems for rural electrification in Saudi Arabia-A way forward for sustainable development. Renew. Sustain. Energy Rev. 2009, 13, 625-633. [CrossRef]

5. Shafiullah, G.M.; Carter, C.E. Feasibility study of photovoltaic (PV)-diesel hybrid power systems for remote networks. In Proceedings of the 2015 IEEE Innovative Smart Grid Technologies-Asia (ISGT ASIA), Bangkok, Thailand, 3-6 November 2015; pp. 1-7.

6. Hatziargyriou, N. MicroGrids; Wiley-IEEE Press: Hoboken, NJ, USA, 2014.

7. Chowdhury, S.A.; Aziz, S.; Groh, S.; Kirchhoff, H.; Filho, W. Off-grid rural area electrification through solar-diesel hybrid minigrids in Bangladesh: Resource-efficient design principles in practice. J. Clean. Prod. 2015, 95, 194-202. [CrossRef] 
8. Bhattacharyya, S.C. Mini-grid based electrification in Bangladesh: Technical configuration and business analysis. Renew. Energy 2015, 75, 745-761. [CrossRef]

9. Guinane, A.; Shafiullah, G.M.; Oo, A.; Harvey, B. Voltage fluctuations in PV penetration on SWER networks-A case study for regional Australia. In Proceedings of the 2012 IEEE Power and Energy Society General Meeting, San Diego, CA, USA, 22-22 July 2012.

10. Rahman, M.M.; Paatero, J.V.; Poudyal, A.; Lahdelma, R. Driving and hindering factors for rural electrification in developing countries: Lessons from Bangladesh. Energy Policy 2013, 61, 840-851. [CrossRef]

11. Shafiullah, G.M. Hybrid renewable energy integration (HREI) system for subtropical climate in Central Queensland, Australia. Renew. Energy 2016, 96, 1034-1053. [CrossRef]

12. The World Factbook. 2017. Available online: https://www.cia.gov/library/publications/the-worldfactbook/geos/bg.html (accessed on 30 March 2018).

13. Mondal, M.A.H.; Denich, M. Assessment of renewable energy resources potential for electricity generation in Bangladesh. Renew. Sustain. Energy Rev. 2010, 14, 2401-2413. [CrossRef]

14. SREDA. Sustainable and Renewable Energy Development Authority (SREDA). 2017. Available online: http:/ / www.sreda.gov.bd/ (accessed on 30 March 2018).

15. IDCOL. Infrastructure Development Company Limited (IDCOL). 2017. Available online: http://www.idcol. org/ (accessed on 30 March 2018).

16. Samad, H.A.K.; Shahidur, R.; Asaduzzaman, M.; Mohammad, Y. The Benefits of Solar Home Systems: An Analysis from Bangladesh; WPS6724; World Bank Group: Washington, DC, USA, 2013.

17. Rahman, S.M.; Ahmad, M.M. Solar Home System (SHS) in rural Bangladesh: Ornamentation or fact of development? Energy Policy 2013, 63, 348-354. [CrossRef]

18. Chakrabarty, S.; Islam, T. Financial viability and eco-efficiency of the solar home systems (SHS) in Bangladesh. Energy 2011, 36, 4821-4827. [CrossRef]

19. Sustainable Energy Access for All. 2011. Available online: http:/ / www.se4all.org/ (accessed on 30 March 2018).

20. Muhammad, D.; Mosleh, M.; Khan, S.H. Assessment and evaluation of solar irrigation system in Bangladesh. In Proceedings of the 2014 3rd International Conference on the Developments in Renewable Energy Technology (ICDRET), Dhaka, Bangladesh, 29-31 May 2014; pp. 1-6.

21. Khan, M.R. Prospect of solar PV based irrigation in rural Bangladesh: A comparative study with diesel based irrigation system. In Proceedings of the 2nd International Conference on the Developments in Renewable Energy Technology (ICDRET 2012), Dhaka, Bangladesh, 29-31 May 2012; pp. 1-3.

22. Shinde, V.; Wandre, S. Solar photovoltaic water pumping system for irrigation: A review. Afr. J. Agric. Res. 2015, 10, 2267-2273.

23. Shoeb, M.A.; Jamal, T.; Shafiullah, G.M.; Rahman, M.M. Analysis of remote PV-diesel based hybrid minigrid for different load conditions. In Proceedings of the 2016 IEEE Innovative Smart Grid Technologies-Asia (ISGT-Asia), Melbourne, Australia, 28 November-1 December 2016; pp. 1165-1170.

24. Homer Energy. HOMER Microgrid Analysis Tool. 2017. Available online: http:/ /www.homerenergy.com (accessed on 29 March 2018).

25. Khan, H.J.; Huque, A.J.; Ahmed, K.; Rahman, R.; Ahmed, T.; Alam, R. Energy usage pattern of off-grid population in Bangladesh. In Proceedings of the 2016 4th International Conference on the Development in the in Renewable Energy Technology (ICDRET), Dhaka, Bangladesh, 7-9 January 2016; pp. 1-4.

26. Khan, M.T.-A.-I.; Sarkar, S.; Hossain, S.; Ahmed, A.U.; Pathik, B.B. The feasibility study of solar irrigation: Economical comparison between diesel and photovoltaic water pumping systems for different crops. In Proceedings of the 2013 International Conference on Electrical Information and Communication Technology (EICT), Khulna, Bangladesh, 13-15 February 2014; pp. 1-5.

27. Mainuddin, M.K.; Chowdhury, R.; Sanjida, L.; Sarker, M.; Shah-Newaz, S.M. Bangladesh Integrated Water Resources Assessment Supplementary Report: Land Use, Crop Production, and Irrigation Demand; CSIRO: Canberra, Australia, 2014.

28. Alam, M.; Bhattacharyya, S. Decentralized Renewable Hybrid Mini-Grids for Sustainable Electrification of the Off-Grid Coastal Areas of Bangladesh. Energies 2016, 9, 268. [CrossRef]

29. Leon, H.M.R.; Shoeb, M.A.; Rahman, M.S.; Ahmed, M.U.; Islam, M.S. Design and economic feasibility analysis of autonomous hybrid energy system for rural Bangladesh. In Proceedings of the 2016 4th International Conference on the Development in the in Renewable Energy Technology (ICDRET), Dhaka, Bangladesh, 7-9 January 2016; pp. 1-6. 
30. Hoque, N.; Roy, A.; Beg, M.R.A.; Das, B. Techno-Economic Evaluation of Solar Irrigation Plants Installed in Bangladesh. Int. J. Renew. Energy Dev. 2016, 5, 73-78. [CrossRef]

31. Reza, S.S.; Sarkar, N.I. Design and performance analysis of a directly-coupled solar photovoltaic irrigation pump system at Gaibandha, Bangladesh. In Proceedings of the 2015 3rd International Conference on Green Energy and Technology (ICGET), Dhaka, Bangladesh, 11 September 2015; pp. 1-6.

32. Arif, M.T.; Oo, A.; Ali, S.; Shafiullah, GM Impacts of storage and solar photovoltaic on the distribution network. In Proceedings of the 22nd Australasian Universities Power Engineering Conference (AUPEC), Bali, Indonesia, 26-29 September 2012.

33. Barley, C.D.; Winn, C.B. Optimal dispatch strategy in remote hybrid power systems. Sol. Energy 1996, 58, 165-179. [CrossRef]

34. Homer Energy. Homer Energy Support. 2016. Available online: http://usersupport.homerenergy.com/ (accessed on 30 March 2018).

35. NASA. Surface meteorology and Solar Energy. 2017. Available online: https://eosweb.larc.nasa.gov/sse/ (accessed on 30 March 2018).

(C) 2018 by the authors. Licensee MDPI, Basel, Switzerland. This article is an open access article distributed under the terms and conditions of the Creative Commons Attribution (CC BY) license (http://creativecommons.org/licenses/by/4.0/). 